\title{
As raízes do Yoga
}

\section{MALLINSON, J.; SINGLETON, M.}

Roots of Yoga

London: Penguin Random House UK, 2017

\section{1 Pamela Siegel I}

1 Universidade Estadual de Campinas. Campinas-SP, Brasil (gfusp@mpc.com.br). ORCID: 0000-0003-3276-1309

Recebido em: 21/11/2019

Aprovado em: 16/12/2019

Revisado em: 21/01/2020

DOI: http://dx.doi.org/10.1590/S0103-73312020300120

Quando Han (2015) nos traz o alerta sobre as características da sociedade do desempenho, por ele chamada de "sociedade do cansaço", em que sofrimentos psíquicos como síndrome de burnout, transtorno de déficit de atenção e hiperatividade e depressão têm relação direta com o modo operatório do capitalismo contemporâneo, devemos nos perguntar se o aumento da procura por práticas integrativas como o Yoga na atualidade não tem o intuito de servir como uma espécie de antídoto a essa exaustáo.

Para que uma técnica terapêutica como o Yoga seja adequadamente compreendida, ensinada e aplicada, é necessário haver um aprofundamento da literatura sobre o tema. Esse livro, Roots of Yoga, nasceu de forma pouco usual, como um projeto de pesquisa que se transformou em texto graças aos fundos coletivos angariados pelo site de financiamento coletivo Kickstarter. Além do mais, ele tem uma pegada sustentável, já que traz o selo do Forest Stewardship Council (FSC, 2019) como chancela de que usa papel de procedência responsável. Contém 11 capítulos organizados entre a introdução e uma linha do tempo de textos importantes, no início, e o glossário, a bibliografia das fontes primárias e secundárias, as notas e os agradecimentos, que ocupam as 103 páginas finais de um total de 540 . 
Os capítulos foram estruturados tematicamente para refletir importantes práticas do Yoga, como as posturas, a respiração e a meditação, e os respectivos resultados dessas práticas, tais como os poderes yóguicos e a liberação. Os autores esclarecem que esses temas não constituem categorias rígidas, e que uma passagem pode aparecer em mais de um capítulo. Cada capítulo segue a seguinte estrutura: uma breve introdução, trazendo uma visão geral dos materiais traduzidos e alguma contextualização histórica, seguida de uma lista de passagens traduzidas e as traduçôes em si. As traduções progridem numa ordem cronológica do começo até o final. Os capítulos mais longos (1, 2 e 5) foram divididos em seçôes temáticas que, por sua vez, foram organizadas cronologicamente.

O capítulo 1, intitulado "Yoga", traz um conjunto de definiçôes do Yoga e caracterizaçôes do yogue, bem como vários sistemas auxiliares (angas) que preparam o praticante para os estados superiores do Yoga, além de exemplos de uma tipologia do Yoga. Contém, também, algumas críticas levantadas contra o Yoga por parte de figuras proeminentes da ortodoxia védica.

Em Preliminaries, o capítulo 2 apresenta as condiçôes que devem ser preenchidas antes da prática do Yoga, que são os obstáculos à prática, como andar em má companhia e o orgulho, e os pontos que favorecem a prática, como um local adequado, uma dieta apropriada e a escuta de discursos filosóficos. Todos os textos concordam com a necessidade de um guru qualificado para alcançar o êxito na prática. Além disso, o capítulo traz as regras (yamas) e observaçôes (niyamas) sistematizadas para a boa prática.

O terceiro capítulo, Posture, trata das práticas posturais que se tornaram quase sinônimos do Yoga no mundo globalizado. Nos textos mais antigos, o termo "ásana" indicava uma posição sentada na qual as práticas da respiração e da meditação pudessem ser realizadas. Contudo, com o advento do hathaYoga, surgem posturas mais complexas, e a partir do século XVII há um aumento no número de posturas.

Breath-control, título do quarto capítulo, trata da respiração, cuja importância, em muitos textos, é tal que conduz aos estados de concentração, meditação e samadhi (iluminação). As traduçóes iniciam com descriçôes de técnicas respiratórias do cânone budista em Pali e do Mahabharata, e incluem passagens de controle de respiração como purificação, como um método de liberação e combinadas com mantras.

No capítulo 5, The Yogic Body, são apresentados, de forma magistral, excertos sobre a fisiologia sutil do yogue, os canais, ventos, o corpo do yogue concebido como 
um microcosmo do universo, e localizaçôes no corpo dos chakras. Há, também, referências à força interior, Kundalini, e ao líquido vital bindu.

As traduções do capítulo 6, intitulado Yogic Seals, tratam do manejo do fôlego ou das energias vitais conhecidas como "selos" (mudras). Há mençôes de gestos das mãos, tipos de sons emitidos e técnicas designadas para manipular e preservar as energias vitais do corpo.

Embora não sejam mencionados nos textos primordiais, e também estejam ausentes de textos mais tardios, os mantras, título do sétimo capítulo, são uma característica fundamental das tradiçôes indianas e foram incorporados ao sistema do Yoga. A repetição de uma variedade de mantras era compreendida como uma manifestação vocalizada de deidades no Yoga tântrico.

Withdrawal, fixation and meditation é o título do capítulo oitavo. O primeiro item lida com a retirada da mente dos objetos de sentidos (pratyahara), enquanto que o segundo, a fixaçáo (dharana), trata da concentração em objetos internos ou externos, ou, em textos tântricos, da progressiva dissoluçáo dos elementos do corpo, com o intuito de chegar à meditação, o terceiro item.

O capítulo nono é sobre Samadhi, liberação ou iluminação. Alguns textos o consideram uma extensão do estágio meditativo. Em textos tântricos é preliminar à meta, que é a uniáo com a deidade. Em textos de hathaYoga, o samadhi pode significar uma espécie de transe, sendo a dissolução (laya) e o som interior (nada) variações dele.

O capítulo décimo tem o curioso título de Yogic Powers. Trata dos assim chamados poderes (siddhis) que surgem com a prática do Yoga, muitas vezes marginalizados ou ridicularizados, mas centrais nos textos yóguicos. Entre as habilidades estariam o poder de dominar outras pessoas. Algumas passagens revelam o tensionamento existente entre as tradições yóguicas que abordam os poderes como fins valiosos em si, e aquelas que os consideram impedimentos para o fim último, que é a liberação.

O último capítulo trata justamente disso, da liberação: Liberation, também conhecida como mukti, moksa, nirvana, kaivalya, entre outros. A natureza precisa da liberação está sujeita a variaçóes significativas do leque de sistemas metafísicos. O capítulo começa com uma descrição antiga da liberação num texto budista, em Pali, e no Mahabharata. Inclui também várias descriçôes de liberação na tradição de Patañjali, bem como em tradições tântricas. 
É uma obra importante para todos os profissionais de saúde, estudantes, pesquisadores, instrutores e praticantes de Yoga, já que com sua difusão global essa prática foi assumindo nuances peculiares aos seus contextos sociais e culturais, como influências das religiôes New Age, da psicologia, da ciência do esporte, da biomedicina, etc. Falta ainda, entretanto, uma compreensão clara de seu contexto histórico, asiático, e a gama das práticas que inclui. Isso se deve em parte à falta de acesso a materiais textuais. Poucas obras, como o Bhagavadgita, os Yogasutras de Patañjali, o HathaYogapradipika e alguns Upanishads são estudadas nos cursos de formação em Yoga, porém fontes textuais mais amplas são pouco conhecidas fora dos ambientes acadêmicos especializados. Dessa maneira, junto com alguns poucos sistemas orientados para as posturas, existe na atualidade uma visão relativamente estreita e monocromática daquilo que o Yoga é e faz, especialmente quando comparado com o amplo espectro de práticas apresentado nos textos pré-modernos sobre Yoga. A importância do livro está relacionada, também, ao fato de que para sua elaboração foram incluídas 155 fontes primárias e centenas de referências secundárias, com uma abrangência pouco vista em outras obras sobre o tema até o presente momento.

Destaca-se que os autores são membros de um movimento de pesquisa (MODERN YOGA RESEARCH, 2017) que se propóe a divulgar estudos sobre o Yoga tanto antigo como moderno, e ajudar os buscadores e pesquisadores no aprofundamento do conhecimento sobre o tema.

O Yoga não foi incluído originalmente na Política Nacional de Práticas Integrativas (BRASIL, 2006) do Sistema Único de Saúde (SUS) e tampouco na reedição de 2015. Foi inserido, no entanto, na Portaria no 719/2011 (BRASIL, 2011), que criou o Programa da Academia de Saúde, com a promoção de práticas corporais e atividades físicas no SUS. Na sequência, em janeiro de 2017, a Portaria no 145/2017 (BRASIL, 2017) alterou os procedimentos na Tabela de Procedimentos, Medicamentos, Órteses, Próteses e Materiais Especiais do SUS para atendimento na Atenção Básica, incluindo o Yoga, que recebeu o número de procedimento 01.01.05.004-6 e o código de origem 01.01.01.007-9. No mesmo ano, em março de 2017, foi assinada a Portaria no 849/2017 (BRASIL, 2017a), que legitimou plenamente a prática do Yoga no SUS. Daí a importância de que, principalmente, os profissionais de saúde que atuam na Atenção Primária, Secundária e Terciária, atualizem seus conhecimentos sobre Yoga.

Não há, entretanto, um censo atualizado das Unidades Básicas de Saúde (UBSs) que ofertam Yoga em nível nacional, porque são 29 as práticas integrativas e 
complementares (PICs) atualmente inseridas no SUS. É tarefa árdua e cara fazer um levantamento de todas essas práticas nos 5.570 municípios do país, além do que os profissionais de saúde responsáveis pelas práticas de Yoga nas UBSs raras vezes publicam suas experiências em revistas indexadas, ou teses e dissertações. Um levantamento no catálogo de teses e dissertações da Capes sobre Yoga (nov. 2019) revelou a existência de 174 trabalhos, sendo 116 de mestrado. O ano de 2018 foi o de maior número de publicaçóes sobre o tema (31), e a grande área de conhecimento com o maior número de publicaçôes é a de Ciências Humanas (36).

Em geral, o Yoga tem sido usado para uma gama de questôes no campo da Saúde e, nas Ciências Humanas, como elemento preparador de corpos e mentes, reflexão sobre valores, bem como pavimentação de caminhos para a busca espiritual. Curiosamente, até onde sabemos, vozes portadoras do discurso decolonial no país não têm se manifestado sobre a presença de técnicas estrangeiras de terapêuticas integrativas, incluído aí o Yoga, na sociedade civil.

Apesar de ser um livro fundamental para os estudiosos da área, ele tem a limitação de estar em língua inglesa e de ser bastante denso. Didático, ele trata sistematicamente da prática do Yoga como ela é apresentada nos textos de referência. Usa uma linguagem técnica, que abre todo um horizonte sobre abordagens do Yoga antes pulverizadas em textos pouco conhecidos, e que agora estão aglutinados numa só obra. No entanto, o leitor não deve esperar um manual com figuras, tabelas, técnicas de ásanas, pranayamas e meditação prêt-à-porter.

\section{Referências}

BRASIL. Ministério da Saúde. Politica Nacional de Práticas Integrativas e Complementares. Brasília: MS, 2006. 92p. . Ministério da Saúde. Portaria n ${ }^{\circ}$ 145/2017, de 12 de janeiro de 2017. Diário Oficial da União, Brasília, DF, nº 10, de 13 de janeiro de 2017. Seção1, p. 32.

. Ministério da Saúde. Portaria n ${ }^{\circ}$ 849/2017, de 27 de março de 2017. Diário Oficial da União, Brasília, DF, no 60, de 28 de março de 2017 Seçãol, p. 68.

. Ministério da Saúde. Portaria no 719/2011, de 7 de abril de 2011. Diário Oficial da União, Brasília, DF, nº 68, 8 de abril de 2011. Seçãol, p. 52.

FOREST STEWARDSHIP COUNCIL (FSC). Disponível em: <https://fsc.org/en>. Acesso em 3 abr. 2019. 
HAN, B. C. Sociedade do cansaço. Petrópolis: Editora Vozes, 2015.

MALLINSON, J.; SINGLETON, M. Roots of Yoga. London: Penguin Random House UK, 2017.

MODERN YOGA RESEARCH. Information and resources for better understanding. Disponível em: <http://www.modernYogaresearch.org/>. Acesso em 5 set. 2017. 